\title{
Effect of Swelling of Chemical Reagents and the Sulfuric-Chromic Acid Bath on Surface Texturizing of Poly(Acrylonitrile-Butadiene-Styrene)
}

\author{
Lorena Magallón Cacho, ${ }^{1,3}$ José de Jesús Pérez Bueno, ${ }^{1, \star}$ Yunny Meas Vong1 \\ and Guy Stremsdoerfer ${ }^{2}$ \\ ${ }^{1}$ Centro de Investigación y Desarrollo Tecnológico en Electroquímica, S.C. Parque Tecnológico Querétaro s/n Sanfandila, \\ Pedro Escobedo, Qro., México. 76703. \\ ${ }^{2}$ Laboratory of Tribology and Dynamics of the Systems UMR 5513 Ecole Central de Lyon. 36 Avenue Guy de Collongue \\ B P 163 69131, Ecully Cedex, France. \\ ${ }^{3}$ CONACYT - Instituto Nacional de Electricidad y Energías Limpias, Av. Reforma 113, Col. Palmira. \\ Cuernavaca, Mor. C.P. 62490. \\ * Corresponding author: E-mail: jperez@cideteq.mx; \\ $+52(442) 2116090,+52(442) 2116001$
}

Received: 02-21-2019

\begin{abstract}
The surface modification of copolymer substrates of Acrylonitrile-Butadiene-Styrene (ABS) is significant for the electroplating industry. The sulfuric-chromic acid bath, used in the Electroless process, conditioning the ABS surface by selective oxidation of poly(butadiene) creating interconnected micro-holes, which allows an excellent mechanical adherence between the metallic film and the substrate. The chromium in its hexavalent form $\mathrm{Cr}(\mathrm{VI})$ is harmful to human beings and the environment being a carcinogenic element. This work shows a surface alteration effect with different types of chemical reagents on ABS surface and its treatment with the sulfuric-chromic acid bath in concentrations below those of the normal process, to analyze the possible application of the electroless process. The use of the different chemical reagents studied favored the alteration of the ABS surface causing various types of surface reactions, which could be shown spontaneously or during the conditioning step.
\end{abstract}

Keywords: Electroless; ABS; Chromium Trioxide; Surface Modification

\section{Introduction}

The metallizing of plastic materials has great industrial importance worldwide. The capability of metallizing plastic substrates represents a significant reduction of costs in both production and transport of materials due to a lower weight compared to metallic products. Metallization of plastics can be obtained by different methods as PVD, CVD, electric arc spraying, ${ }^{1}$ and other chrome (VI)-free methods. ${ }^{2}$ The most used process of metallizing non-conductive materials is known as "Electroless," which allows metallizing autocatalytically, in the absence of electric current, non-conductive materials that cannot be directly metallized by a conventional electrolytic process. ${ }^{3,4}$ Once it has formed a thin conductive layer $(\mathrm{Ni}$ or $\mathrm{Cu}$ ), an electrolytic deposit grows a metallic film and provides the final finishing. ABS metallized pieces even can be reprocessed by chemical pickling. ${ }^{5}$

The surface of the piece has to be conditioned so that an excellent adherence exists between the foil and the substrate. With this purpose, in the Electroless process, there is the etching stage, which creates favorable conditions to carry on the surface metallization in a correct way and has the desired adhesion. The etching is performed with a mixture of $\mathrm{CrO}_{3}$ and $\mathrm{H}_{2} \mathrm{SO}_{4}$, which in certain conditions of temperature and elevated concentrations of $\mathrm{Cr}(\mathrm{VI})$, modifies the surface of the substrate. ${ }^{3}$

The most used not-conductive substrate for metallizing is the thermoplastic copolymer Acrylonitrile-Butadiene-Styrene (ABS). Its conformation consists of a continuous matrix of the copolymer poly(styrene-co-acrylonitrile) and a phase segregated throughout the volume in the form 
of microspheres of poly(butadiene). The superficial spheres of poly(butadiene) being in contact with the sulfuric-chromic acid bath are oxidized selectively, leaving empty sites (microvoids) interconnected with the frequency that the poly(butadiene) sites had (Figure 1). Subsequently, the growth of the metallic film is performed from inside the voids outward promoting mechanical adhesion. ${ }^{6-8}$

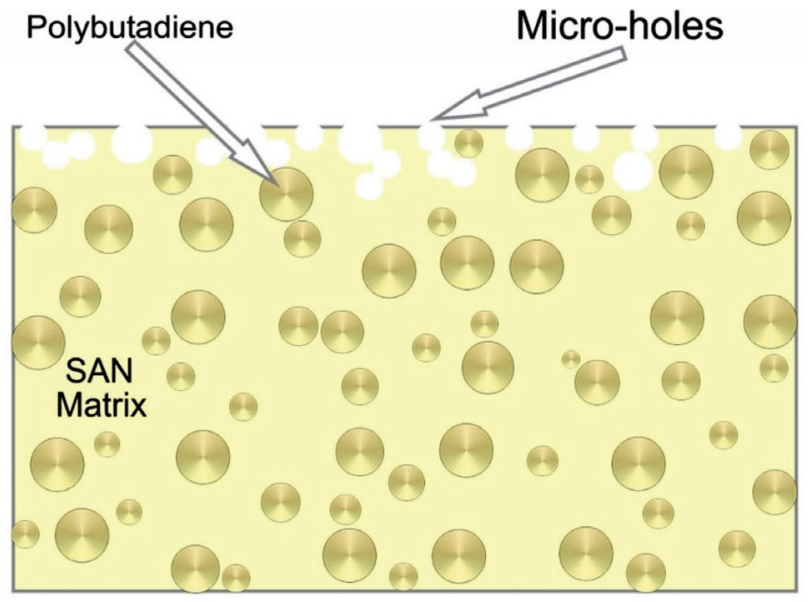

Figure 1. Schematic representation of the poly(butadiene) distribution in the matrix of poly(styrene-acrylonitrile) (SAN) and micro-voids formation due to selective etching with the sulfuric-chromic acid bath.

Numerous approaches were reported for metallization of ABS, polyimide and other polymers with surface modification by different methods such as photocatalysis, ${ }^{9,10}$ plasma, ${ }^{11-13}$ molecules grafted, ${ }^{14}$ and silane coupling. ${ }^{15}$

Although the use of the sulfuric-chromic acid bath results in an excellent appearance and adhesion of the metallic deposit, reason for which it has been used on a large scale per decades, it has major disadvantages. The $\mathrm{Cr}$ (VI) is carcinogenic, which represents serious risks to humans and the environment. ${ }^{16,17}$ Also, special handling of this type of residues involves additional costs to industrial processes, especially in the effluent treatment systems and optimal control of the manufacturing process to prevent labor hazards. Therefore, it is of primary importance the study of alternatives to create a conductive layer on the surface of ABS with an environmentally acceptable process, doing a partial or total replacement of the current method.

The use of electroless platting has been extended to these objects designed and then $3 \mathrm{D}$ printed using ABS. Stages of surface preparation for the process such as aluminum paint paste and aluminum epoxy paste have been used for electroless coating varying temperature and deposition time. ${ }^{18}$

The electroless process have been combined with other techniques such as Laser Direct Structuring (LDS) ${ }^{19}$ or Selective Surface Activation Induced by Laser (SSAIL) ${ }^{20}$ using organocopper compounds for portable electronics. This allows obtaining precise metallized patterns with selective fabrication onto ABS finished with electroless copper plating (ECP).

In the last decade, there have been a very intensive quest for improving the etching treatment for ABS especially for copper and nickel plating. 19,21,22 There are many different alternatives proposed in these studies and all of them with the same target, avoid the use of $\mathrm{Cr}^{6+}$ in metallization of ABS and other polymers. ${ }^{22}$ The studies focused in substituting the sulfuric-chromic acid bath, and among many different procedures, the use of $\mathrm{KMnO}_{4}$ have been one of the more important points of reference. ${ }^{21,23}$

Nowadays, the swelling of substances into polymers are mainly used in hydrogels for making of them superabsorbent composite ${ }^{24}$ and conferring them some characteristics by the swelling of substances such as ionic, ${ }^{25,26}$ anti-microbial, ${ }^{27}$ fuels, ${ }^{28}$ fertilizers. ${ }^{29}$ There are other works focused in the humidity absorption into polymers. ${ }^{26,30,31}$

In the case of the swelling for electroless process, resent works reported the use of swelling for increase the adhesion strength of a polymer such as polyimide and an electroless copper layer with a $\mathrm{TiO}_{2}$ photocatalytic treatment. ${ }^{32}$

There is a proposal of a surface swelling-induced strategy-based facile electroless deposition method to prepare copper circuits on various polymer substrates such as ABS, polyimide, and silicon rubber. ${ }^{33}$ There are reports of an $\mathrm{Ag}$ catalytic process using swelling impregnation pretreatment method for electroless nickel deposition on Kevlar fiber, which show both corrosion resistance and high tensile strength. ${ }^{34}$

There are some works that, as an alternative to swelling, use voids on the surface to trap water and cause an effect of hydrophilicity and self-cleaning by a direct contact of external drops with the water already on the surface. ${ }^{35}$

There are works related to the deposition of some layers on a swelling polymer that leads to the formation of uniform wrinkles after the release of polymer strain because of isotropic polymer elongation. Particularly, conductive silver wrinkles have been grown on an elastomer by combining polymer swelling with electroless deposition for ultrasensitive pressure sensors. ${ }^{36}$

For such a reason, this work presents the study of various chemical reagents that pre-treat, through a chemical stage, the surface modification of ABS with subsequent treatment with the sulfuric-chromic acid bath at low concentrations. This pretreatment is performed as a stage before that of conditioning within the Electroless process. The final objective, using chemical reagents before the sulfuric-chromic acid bath, is obtaining a rough surface using low concentrations of $\mathrm{Cr}(\mathrm{VI})$ that allows having an excellent adherence between the substrate and the autocatalyti- 
cally obtained plating through the Electroless process.

The selection criteria for the chemical reagents were based on the dissolution times of the polymers, their flashpoints and chemical resistance presented by the ABS in the presence of the selected reagents, for a $48 \mathrm{~h}$ period. Saubestre ${ }^{37}$ mentioned that the use of nitric acid and methanol favors solvation of the polymer surfaces, favoring its oxidation when performing the etching with the sulfuric-chromic acid bath at lower concentrations $(75 \mathrm{~g} / \mathrm{L}$ $\left.\mathrm{CrO}_{3}\right)$ than required by the usual process $\left(350 \mathrm{~g} / \mathrm{L} \mathrm{CrO}_{3}\right)$.

\section{Experimental}

The two different types of ABS used in this study were A) oval ABS pieces from the brand Nacobre (without dye - without white powder of $\mathrm{TiO}_{2}$ in rutile form) and $\mathrm{B}$ ) ABS plates from the brand Senosan, AA50 White 1000 (with dye, having rutile $\mathrm{TiO}_{2}$ for provide a white appearance). The reason for including two types of ABS, with or without white titania powder and both broadly used in the industry, was the expected change or influence on the swelling and metallization process.

The characterization of the ABS was done by Infrared Spectroscopy (FT-IR) with a Thermo Nicolet FT-IR model Nexus was used identifying the bands corresponding to the ABS, according to each of the functional groups.

A dissolution using industrial grade acetone was prepared for identification of the dye present in the ABS Senosan AA50 White 1000. The obtained precipitate was left to dry and was subsequently milled. Later, it was characterized by X-ray Diffraction (XRD), with a Bruker AXS, model D8Advance using a $40 \mathrm{~mA}$ and $40 \mathrm{kV}$, which allowed to obtain the diffractograms of the crystalline components.

The analysis of molecular weights for both types of ABS was performed using the technique of Gel Permeation Chromatography (GPC) with $20 \mathrm{mg}$ of sample in 10 $\mathrm{mL}$ of HPLC grade THF. The temperature in the oven was $40{ }^{\circ} \mathrm{C}$ and kept under mechanical stirring for $2 \mathrm{~h}$. Standards of poly(styrene) were used and the equipment utilized was a Chromatograph of Permeation in Gel of the brand Waters.

The conventional etching tests were performed by dipping ABS (without dye) in the sulfuric-chromic acid bath. The concentration was $350 \mathrm{~g} / \mathrm{L}$ of $\mathrm{CrO}_{3}(99.2 \%$, JT Baker) and 22\% v/v $\mathrm{H}_{2} \mathrm{SO}_{4}$ (98.4\%, JT Baker). The mixture was stirred and heated to an average temperature of $75{ }^{\circ} \mathrm{C}$ and, to determine the degree of attack on the plastic surface, tests were performed at three different times: 4,10 and 15 minutes, which served as references of industry-wide standard procedure in conditioning the surface of ABS.

The ABS pieces (without dye) were submerged in 30 $\mathrm{mL}$ of four different organic solvents separately: Diethyl oxalate $(99+\%$, Aldrich) for $7 \mathrm{~min}$, phenetole (99\%, Aldrich) for 5, 10, 20 and $30 \mathrm{~s}$, industrial grade acetone at
$10,30,50$ and $80 \% \mathrm{v} / \mathrm{v}$ with methanol (99.9\%, JT Baker), and $30 \mathrm{~mL}$ of nitric acid (65.6\%, JT Baker), all these tests at room temperature. Likewise, tests were conducted dipping ABS (with dye) in a solution of $\mathrm{KMnO}_{4}(99.8 \%$, JT Baker) at a concentration of $0.5 \mathrm{M}$ with a time of experimentation of $15 \mathrm{~min}$. The solution was subjected to heating with an average temperature of $78^{\circ} \mathrm{C}$ and stirring during the tests. The pieces were rinsed with deionized water and allowed to dry at room temperature. Subsequently, treatments were performed using the sulfuric-chromic acid bath at $\mathrm{CrO}_{3}$ concentrations of $350 \mathrm{~g} / \mathrm{L}$ and $75 \mathrm{~g} / \mathrm{L}$.

Hardness measurements were performed with Vickers micro-indentation technique on substrates of $A B S$ (without dye) having as pretreatment immersion into phenetole, diethyl oxalate, Acetone, and the sulfuric-chromic etching, and on a substrate without pretreatment which served as a reference. We used a Digital Alpha MXT-Microhardness Tester brand Matsuzawa with a load of $200 \mathrm{~g}$.

The contact angle measurements were performed with a Digidrop GBX, Scientific Instruments. The surface images were obtained by Scanning Electron Microscopy (SEM) with a JEOL equipment, model JSM-5400LV at a magnification of $5000 \mathrm{X}$ and voltage of $20 \mathrm{kV}$. Adhesion measurements were performed using the "Cross-Cut Tape Test" according to ASTM method D-3359, using a kit manufactured by Precision Gage \& Tool Co. The measurement of reflectance was done with an Ocean Optics spectrometer, Inc. Model USB2000 with fiber extension and an integrating sphere suspended approximately $4 \mathrm{~mm}$ over an ABS plate immersed into a solution of electroless Ni.

\section{Results and Discussion}

\section{1. Characterization of ABS (FT-IR)}

The ABS has the following four characteristic bands: a) $2240 \mathrm{~cm}^{-1}$ corresponding to the vibration of the nitrile groups $(C \otimes N)$ present in the acrylonitrile; b) $970 \mathrm{~cm}^{-1}$ belonging to the deformation of the $\mathrm{CH}$ groups trans- $\mathrm{R} \mathrm{H}$ $\mathrm{C}=\mathrm{C} \mathrm{H} \mathrm{R}$ present in the poly (butadiene); c) $760 \mathrm{~cm}^{-1}$ and d) $700 \mathrm{~cm}^{-1}$ characteristic of the vibrational modes of the benzene ring monosubstituted, present in the styrene. Figure 2 shows the spectra obtained resulting from the characterization of the two different types of ABS studied in this work, where the characteristic bands were identified for the three constituent monomers.

Figure 3 shows the X-ray powder diffractogram for the analysis of a solution of ABS Senosan AA50 White 1000 , where the peaks are identified for the $100 \% \mathrm{TiO}_{2}$ as a rutile phase. It is widely known that the rutile phase has a lower photocatalytic activity compared to the anatase phase, ${ }^{38}$ which added to the encapsulating polymer by photo-oxidation restricts and prevents the formation of $\mathrm{OH}$ radicals with water. Therefore, it is possible to discard the material used in this conformation for photocatalysis in the case that the pieces would be illuminated with UV. 


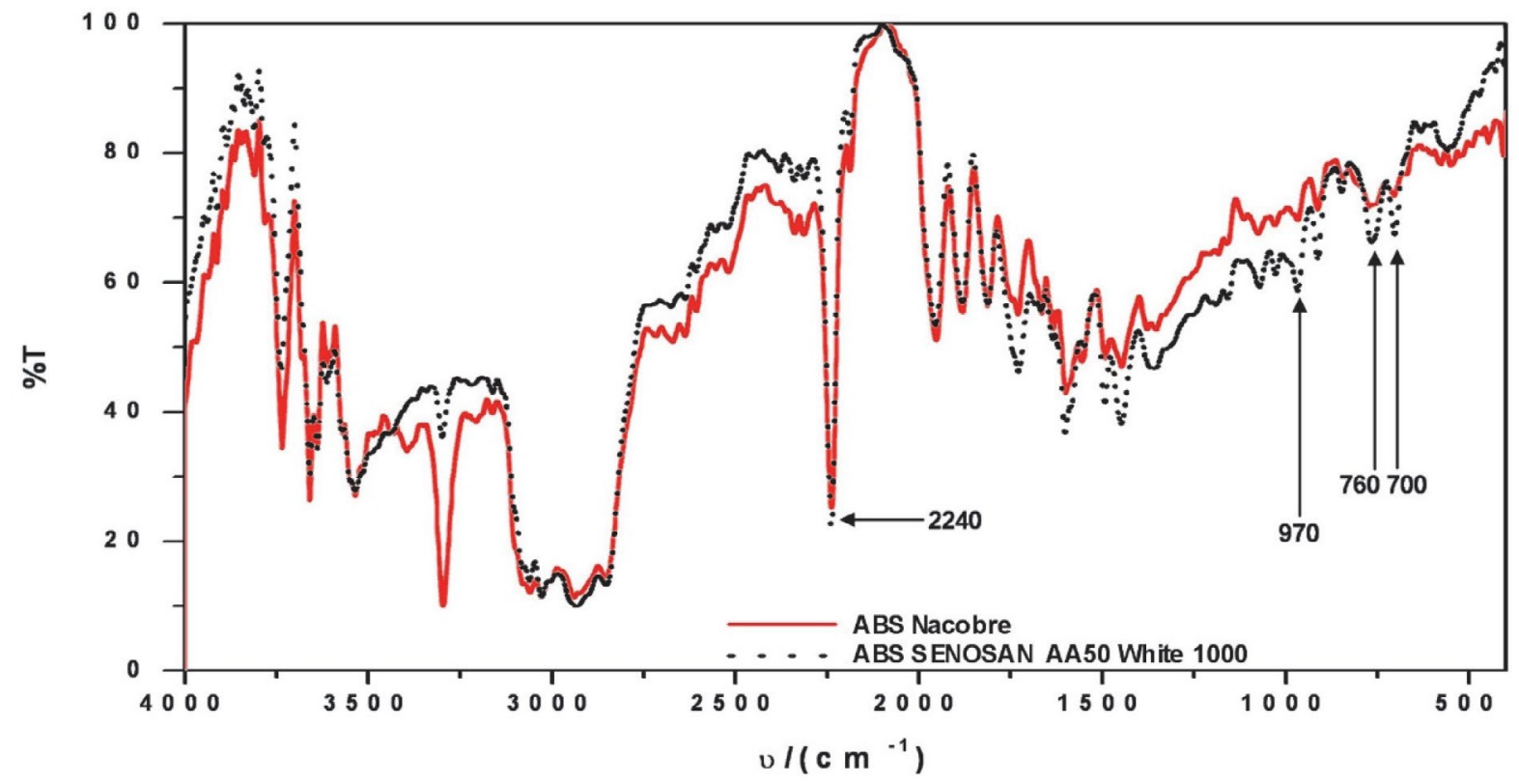

Figure 2. FT-IR spectra of ABS from Nacobre and SENOSAN AA50White 1000.

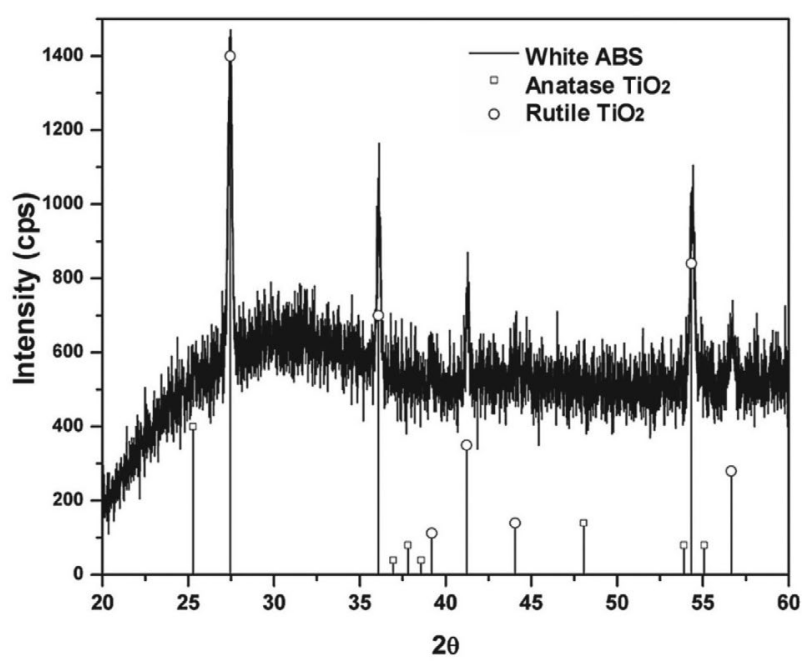

Figure 3. X-ray diffractogram of ABS dissolution with dye.

The molecular weight measured by GPC technique for ABS without dye was about 136.26 Daltons and for the ABS with dye was about 169.13 Daltons. It is important to know that there is not a marked difference in molecular weights between the polymers, which have been studied comparing their behavior with organic solvents, as there is a significant dependence of this parameter.

\section{2. Conditioning Tests with the Sulfuric- Chromic Acid Bath}

The sulfuric-chromic acid bath is influenced by two factors, the concentration of the bath and the immersion time. The combination of which has resulted in varying degrees of attack on the substrate surface. Figure 4 (a) shows the micrograph corresponding to the surface for one piece without coloring and without treatment, which was taken as a reference to the original substrate conditions. Figure 4 (b, c, d) shows the effect caused by etching at different times. The formation of micro-holes in the samples was notorious, which had an average size of about $0.26 \mu \mathrm{m}$ for the sample with 4 minutes of treatment. Comparing the images reveal the severity of the surface modification for longer times of treatment (10 and $15 \mathrm{~min}$ ) with an average hole size of about $0.51 \mu \mathrm{m}$. The etching of the polybutadiene domains was caused by the sulfuric-chromic acid bath. This bath is highly oxidant and the chrome reacts with the polymer by the oxidation reaction of $-\mathrm{C}=\mathrm{C}$ - bonds in the polybutadiene $-\left[-\mathrm{CH}_{2}-\mathrm{CH}=\mathrm{CH}-\right.$ $\left.\mathrm{CH}_{2}\right]_{\mathrm{n}}$ - leaving some polar groups in the surface such as $-\mathrm{OH}$ and $-\mathrm{COOH} .{ }^{39}$ The polybutadiene is washed away from the surface leaving voids as shown in Fig 4b, 4c, 4d. Polybutadiene is very sensitive to oxidative degradation. There are many works showing details about the oxidation and foto-oxidation processes of polybutadiene, ${ }^{40}$ polystyrene, ${ }^{41}$ polyacrilonitrile, ${ }^{41}$ and other polymers. ${ }^{42,43}$

\section{3. Test for Surface Texturizing with the Sulfuric-Chromic Acid Bath}

When the mixture had been used continuously, the concentration may vary due to the reduction of $\mathrm{Cr}^{+6}$ to $\mathrm{Cr}^{+3}$ causing that its oxidizing power was diminished. Table 1 shows the contact angle values obtained for different treatments. The value of the contact angle for the sulfuric-chromic treatment increases considerably, comparing 


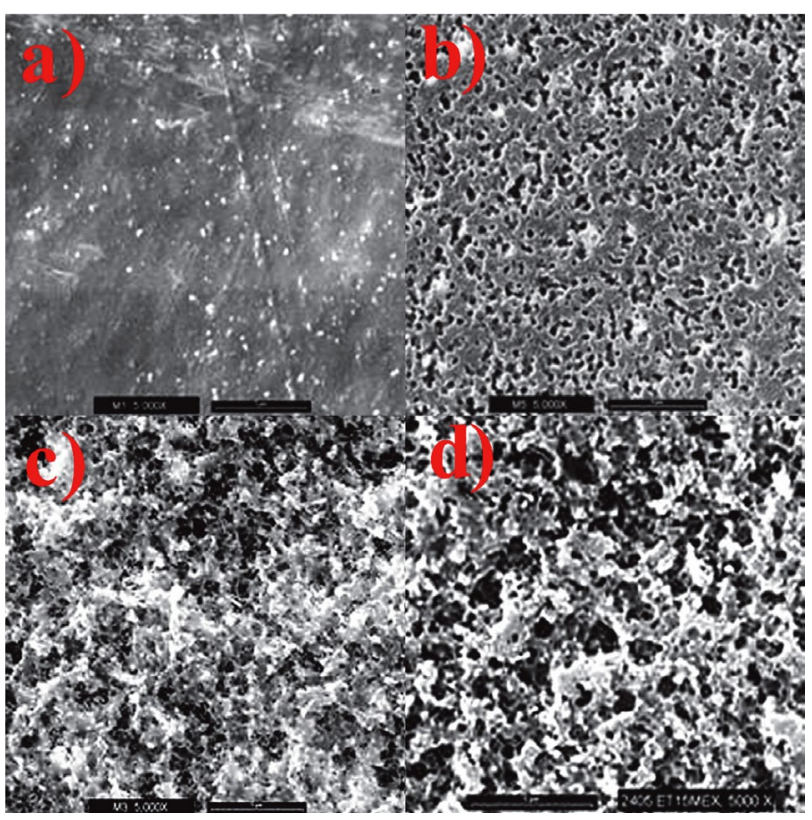

Figure 4. ABS SEM micrographs of (a) untreated; (B) and (c) etching with the sulfuric-chromic acid bath $(350 \mathrm{~g} / \mathrm{L}), \mathrm{T}_{\text {avg }}=75^{\circ} \mathrm{C}, \mathrm{t}_{\mathrm{inm}}$ $=4$ and $10 \mathrm{~min}$ of undyed parts, respectively; (D) $350 \mathrm{~g} / \mathrm{L}, \mathrm{T}_{\text {avg }}=75$ ${ }^{\circ} \mathrm{C}, 15 \mathrm{~min} \mathrm{t}_{\mathrm{inm}}=$ white $\mathrm{ABS}$ samples. The scale bars in all cases were $1 \mu \mathrm{m}$ at $5000 \mathrm{X}$

it to an untreated substrate, which was attributable to the influence of the formation of a highly rough surface. However, the factor that the water droplet can be held in a smaller number of points is not the only factor, which is only the physical aspect. There is also a chemical modification factor, which is susceptible to changes over time due to interaction with the environment. This is evidenced by the affectation of the adhesion and the homogeneity of the metal layer deposited with the Electroless process, in the cases that the samples were stored after pretreatment.

\section{4. Tests with Chemical Reagents}

\section{4. 1. Diethyl Oxalate}

Diethyl Oxalate is an excessively aggressive solvent for the ABS structure. The tests resulted in a generalized softening of the ABS plates and loss of shape of the parts. Also, a white precipitate product from the dissolution of ABS in the solvent was observed. Subsequently, the pretreated substrate was introduced into the sulfuric-chromic acid bath. However, all the absorbed solvent reacted abruptly, showing an effervescence effect and causing the samples to become semi-transparent and olive-colored (Fig. 5 (b)) as compared to an untreated substrate (Fig. 5 (a)). The effect of deformation on the ABS structure, with the use of this type of solvent and its reaction with the sulfuric-chromic acid bath, makes it difficult to be used as an ABS pretreatment system.

\section{4. 2. Phenetole}

The pieces treated with the solvent at different treatment times showed a slight softening of the surface proportional to the immersion time, there were not discoloration, surface wear or deformation. However, the solvent remained adsorbed on the piece, giving off a very intense characteristic odor. It was observed that the softening effect of the surface remained even 24 hours after the treatment was done. This effect may help to reduce the usage time of the sulfuric-chromic acid bath since the surface was previously softened. However, the obtained effect when conducting the chemical treatment on the piece with $30 \mathrm{~s}$ by dipped was extremely severe. After a few seconds, the solvent adsorbed on the surface violently reacted with the sulfuric-chromic acid bath, leaving the surface with a burnt appearance and an olive green color (Fig. 5 (c)).

Table 1. The contact angles of ABS pieces for different surface treatments.

\begin{tabular}{lc}
\hline ABS substrate & $\boldsymbol{\theta}$ \\
\hline (a) Without treatment & $57.9^{\circ}$ \\
(b) Sulfuric-chromic acid bath $10 \mathrm{~min}$ & $113^{\circ}$ \\
(c) Sulfuric-chromic acid bath $15 \mathrm{~min}$ & $119.8^{\circ}$ \\
(d) $\mathrm{KMnO}_{4}$ & \\
\hline
\end{tabular}




\section{4. 3. Acetone}

The dipping of ABS in industrial grade acetone, results in a rapid softening, deformation and dissolution of it, resembling a plastic being melt with a sticky consistency. The piece loses its original semi-transparent yellow color. ABS residues were observable in the solvent due to the surface wear. The results were similar in very short immersion times and rapid drying of the acetone on the surface. Even with this result, it was decided to continue with the chemical pretreatment of the sulfuric-chromic conventional treatment. As with the other cases, acetone adsorbed on the surface reacted quickly when in contact with the conventional etching bath, causing a change of appearance on the substrate. A thin white film was formed on the surface which was easily removed (Fig. 5 (d)). The ABS is completely soluble in acetone with an immediate effect.

\section{4. 4. Methanol}

The use of methanol was not visibly aggressive for $\mathrm{ABS}$ and the treatment did not show color changes or modification of the substrate. However, when testing the etching with the sulfuric-chromic acid bath, it was observed that the surface rapidly reacted, which was indicative that the methanol was adsorbed on the surface of the ABS. As in other cases, there was a change from the original color to a dull color on the surface and in the back of the piece were observed bubbles formed by the plastic as a result of the reaction (Fig. 5 (e)). a)

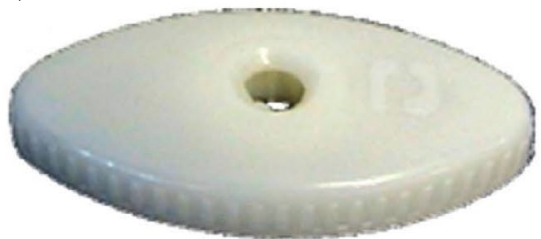

d)

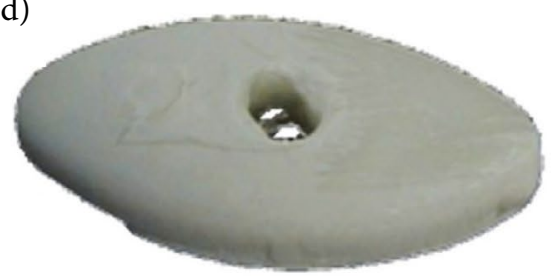

b)

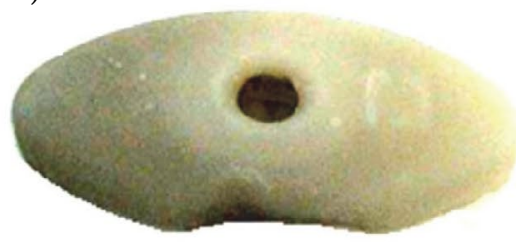

e)

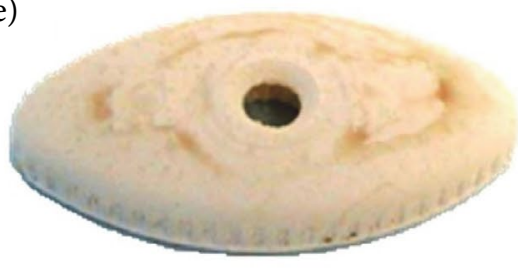

c)

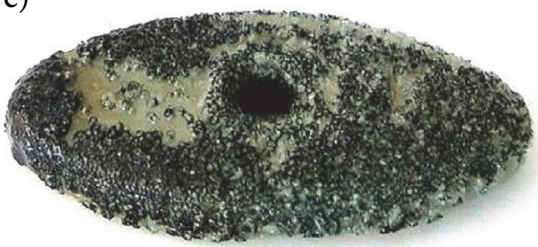

f)

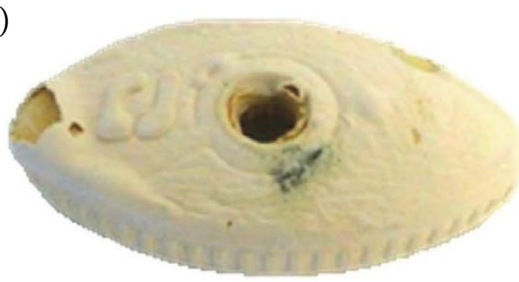

Figure 5. A piece of ABS without dye: (a) without treatment, with chemical treatment, and conditioning with the sulfuric-chromic acid bath (350 g/L): (b) Diethyl Oxalate; (c) phenetole; (d) Acetone; (e) Methanol; with chemical treatment and conditioning with sulfuric-chromic mixture (75g/L): (f) nitric acid.
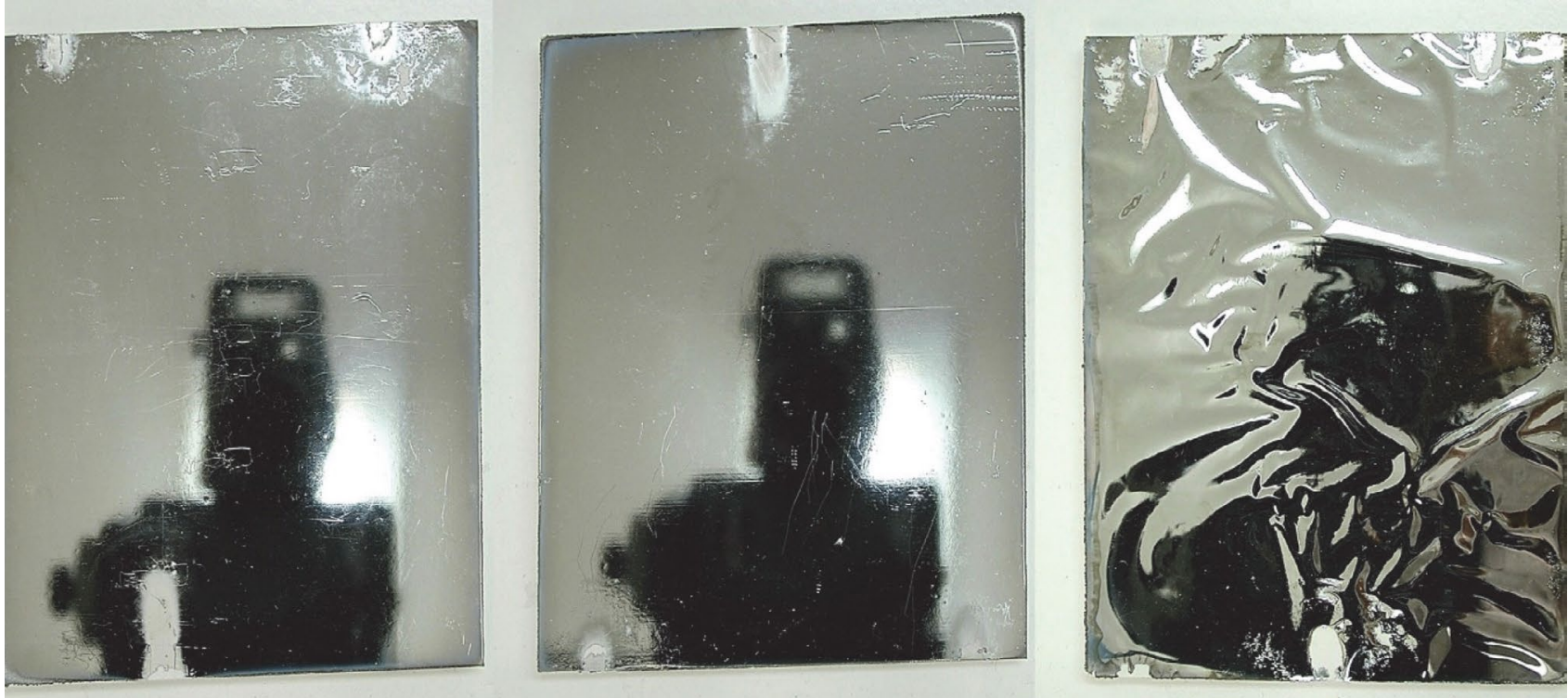

Figure 6. White-ABS premetallized with Ni-JetMetal ${ }^{\circledR}$ and electrolytic deposition of $\mathrm{Cu}-\mathrm{Ni}$-Cr: (a) sulfuric-chromic bath for $10 \mathrm{~min}$; (B) sulfuric-chromic bath for $15 \mathrm{~min}$; (C) $\mathrm{KMnO}_{4}$ for $15 \mathrm{~min}$. 


\section{4. 5. Nitric Acid}

The ABS pieces without dye were immersed in nitric acid and showed a slight softening of the surface, only for as long as it remained wet, losing this feature when dried. It was observed the discoloration and swelling of the substrate. After the pretreatment with nitric acid, the etching was carried out using the sulfuric-chromic acid bath but at a lower concentration $(75 \mathrm{~g} / \mathrm{L})$. In this case, the adsorbed nitric acid reacted causing a cracked surface and with the formation of small lumps, accompanied again by a color change. Figure 5 (f) shows sequentially the physical effects on each of the pretreatment steps, beginning with an untreated piece, which was then treated with nitric acid and subsequently with the sulfuric-chromic acid bath.

\section{4. 6. Potassium Permanganate $\left(\mathrm{KMnO}_{4}\right)$}

Treatment of ABS with $\mathrm{KMnO}_{4}$ showed a noticeable color change on the substrate. It did not show a softening of the surface as in the previous cases. The contact angle value obtained for the pretreated surface with potassium permanganate was slightly larger than for the untreated piece. This could be due to the existence of a small modification of the surface, which increased by the increase of surface roughness as in the case of the contact angle values for the sulfuric-chromic acid bath treatment. Unlike the other pretreatments, the pieces after potassium permanganate were not treated with the sulfuric-chromic acid bath. The premetallized with nickel under JetMetal Technologies technique and subsequently performed the electrodeposition of Copper-Nickel-Chromium (Fig. 6 (c)). However, in the adhesion tests by cross-cut adhesive tape done according to ASTM method D-3359, the adhesion rating obtained was $0 \mathrm{~B}$. This value indicates that even though the contact angle for this pretreatment is higher than that of a normal substrate, the possible modification of the surface is not sufficient for obtaining a bond similar to the sulfuric-chromic acid bath (Table 2). Figure 6 (a) and Figure 6 (b) show the comparison between two ABS pieces with the sulfuric-chromic acid bath pretreatment for 10 and $15 \mathrm{~min}$, respectively. Both were metallized conventionally. Compared to potassium permanganate substrate (Fig. 6 (c)), it is notorious the influence of the pretreatment before metallization in both appearance and adhesion.

Figure 7 shows a reflectance graph of an ABS sample acquired in situ during the nickel deposition process by the Electroless conventional process. The decrease in intensity of reflected light on the ABS pretreated surface can notoriously observe as it grows a dark layer of nickel. The nickel deposit takes a few seconds to be perceptible, which is reflected in the measurement. Electroless nickel solution, with a characteristic green hue, slightly contributes to the absorption of light, particularly at the ends of the graph.
Table 2. Adhesion results for coatings on surfaces with different treatments (ASTM D-3359).

\begin{tabular}{lc}
\hline ABS substrate & $\begin{array}{c}\text { Adhesion } \\
\text { classification }\end{array}$ \\
\hline $\begin{array}{l}\text { Sulfuric-chromic, } 10 \text { min. + Ni, Electroless + } \\
\text { Cu-Ni-Cr Electrolytic }\end{array}$ & $5 \mathrm{~B}$ \\
$\begin{array}{l}\text { Sulfuric-chromic, } 10 \text { min. + Ni, JetMetal }+ \\
\text { Cu-Ni-Cr Electrolytic }\end{array}$ & $4 \mathrm{~B}$ \\
$\begin{array}{l}\text { Sulfuric-chromic, } 15 \text { min. + Ni, JetMetal }{ }^{\circ}+ \\
\text { Cu-Ni-Cr Electrolytic }\end{array}$ & $4 \mathrm{~B}$ \\
$\begin{array}{l}\mathrm{KMnO} \\
\mathrm{Cu} \text {-Ni-Cr Electrolytic }\end{array}$ & $0 \mathrm{~B}, 15$ min. \\
\hline
\end{tabular}

The characterization results of Vickers hardness (Table 3) shows the influence of different chemical pretreatments hardness values for the ABS substrate. The acetone was the chemical that affects more the substrate with a decrement of $3.7 \mathrm{HV}_{200}$ comparing to the reference value for the ABS without treatment $\left(11.5 \mathrm{HV}_{200}\right)$. The sulfuric-chromic acid bath pretreatment did not significantly affect the hardness value of the ABS. However, the solvent adsorbed on the surface significantly reduce the hardness of the material due to structural changes that suffer the polymer surface by reaction with such solvents. The severity of the attack on substrates with Diethyl oxalate pretreatment with nitric acid and subsequent attack of the sulfuric-chromic acid bath (Fig. 5 (b) and $5(\mathrm{f})$ ), blocked the hardness measurement since the surface characteristics not allowed to obtain the trace formed by the indentation tip on the substrate surface.

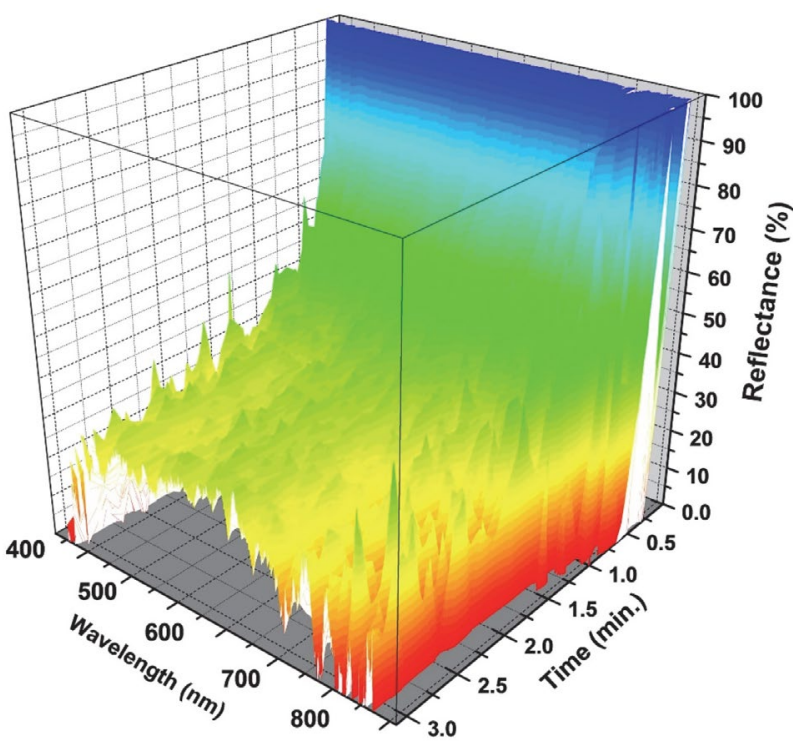

Figure 7. Reflectance graph for the growth of a nickel film on ABS. 
Table 3. Vickers hardness measurements on ABS surfaces with different treatments.

\begin{tabular}{lc}
\hline ABS substrate & $\mathbf{H V}_{\mathbf{2 0 0}}$ \\
\hline Without treatment & 11.5 \\
Sulfuric-chromic acid bath & 11.3 \\
Diethyl Oxalate & 12.9 \\
Phenetole & 9.6 \\
Acetone & 7.8 \\
\hline
\end{tabular}

\section{Conclusions}

The simple reduction of the concentration of $\mathrm{Cr}(\mathrm{VI})$ in industrial baths may represent a major environmental and economic impact. However, the results of the experimentation show that the nitric acid and methanol are not viable chemical treatments before conditioning with the sulfuric-chromic acid bath at low concentrations, contrary to what reported in the literature. The main reason for this to happens is due to the adsorption of these chemical reagents on the surface of the polymer, which on contact with chromium-sulfuric mixture react violently, causing the surface modification of the material but without complying with the requirements to have the desired final appearance. The same effect was presented by using diethyl oxalate, phenetole, and acetone.

The swelling of solvents is not propitious before the use of the sulfuric-chromic acid bath. It could be used a chemical treatment that involves adsorption of molecules on the surface of the treated parts, either before other conventional or novel plating process, for example, JetMetal Technologies. This because of possible deformation after effects such as samples or loss of adhesion of the deposit.

In the case of $\mathrm{KMnO}_{4}$, although it has been reported as an excellent pretreatment system to replace $\mathrm{CrO}_{3}$ for the conditioning step of the Electroless process. The adhesion results indicate that there is not enough modification of the substrate for obtaining an excellent adhesion in accordance with the ASTM D-3359 method.

There are two contribution to the observed contact angle results. First, the chemical composition of the surface may change for the measurements in Table 1 but this was not possible to been proved by the FTIR technique. Second, the surface morphology was severely changed becoming coarse. The separation among the high points in these new surfaces going to conditioning the increase of the contact angle, especially when comparing with the water drop size. We propose that when few of these high points support the drop, the contact angle increases making the surface more hydrophobic, such as in the case of the sample with sulfuric-chromic acid bath with $15 \mathrm{~min}$, or in some sections even superhydrophobic.

All the samples showed swelling of the tested solvents. The effect of acetone resulted as the most notorious change. Since the effect of the sulfuric-chromic acid bath was severe on most of the samples, there was not a direct observed difference between the two types of ABS (without or with $2 \mathrm{wt} \%$ of white powder of $\mathrm{TiO}_{2}$ in rutile form).

\section{Acknowledgments}

This work was done under the auspices of the Mexican Council for Science and Technology CONACYT, through the projects CEMIE-Sol No. 207450 P18, P62, P96; Graphenic Materials National Laboratory No. 293371. Thanks to The World Bank and the Energy Secretariat for the grant of the PRODETES Price, No. 002/2017/PRODETES-PLATA. Also, the first author acknowledges CONACYT for his graduate fellowship.

\section{References}

1. S. Nigam, S. S. Mahapatra, S. K. Patel, Materials Today: Proceedings 2018, 5, 8446-8453.

DOI:10.1016/j.matpr.2017.11.540

2. D. Lehmann, J. Nagel, P. Zimmermann, P., Schlenstedt, K. Galvanotechnik 2018, 109, 43-48.

3. A. Fares Karam, G. Stremsdoerfer, in: K. L. Mittal (Ed.): Metallized Plastics 5 \& 6: Fundamental and Applied Aspects, CRC Press, London, 1998, pp. 137-144.

DOI:10.1201/b11958

4. P. C. Rodríguez, in: Galvanoplastia Aplicada Teoría y Práctica, Alsina, Buenos Aires, Argentina, 1998, pp. 7.

5. A. P. Kurek, R. G. Moll, G. Herbst, M. E. R. Dotto, N., J. Appl. Poly. Sci. 2018, 135, 46131. DOI:10.1002/app.46131

6. J. J. Kuzmik, in: O. Glenn Mallory, J. B. Hajdu (Eds.): Electroless Plating: Fundamentals and Applications, American Electroplaters and Surface Finishers Society, Orlando, Florida, 1990, chapter 14 .

7. N. Platzer, in: American Society of Electroplated Plastics, Standard and Guidelines for Electroplated Plastics, Prentice-Hall, Englewood Cliffs, N. J., 1972, chapter 1.

DOI:10.1002/pol.1982.130200910

8. J. B. Hajdu, G. Krulik, in: L. J. Durney, Van Nostrand Reinhold (Eds.): Electroplating Engineering Handbook, New York, 1984, pp. 202-205.

9. L. Magallón Cacho, J. J. Pérez Bueno, Y. Meas Vong, G. Stremsdoerfer, F. J. Espinoza Beltrán. Surf. Coat. Tech. 2011, 206, 1410-1415. DOI:10.1016/j.surfcoat.2011.09.005

10. X. Geng, Q. Qiang, J. Zhao, J. Yang, Z. Wang, J. Adhes. Sci. Tech. 2015, 29, 705-715.

DOI:10.1080/01694243.2014.1001960

11. N. Inagaki, K. Narushima, M. Morita, J. Adhes. Sci. Tech. 2006, 20, 917-938. DOI:10.1163/156856106777657797

12. J. R. Bartoli, I. Y. Abbe, M. N. P. Carreño, I. Pereyra, E. G. Fernandes, AIP Conference Proceedings 1981, International Conference on Times of Polymers and Composites: From Aerospace to Nanotechnology 2018, 020162.

DOI:10.1063/1.5046024 
13. G. Rozovskis, J. Vinkevičius, J. Jačiauskiene, J. Adhes. Sci. Tech. 1996, 10, 399-406. DOI:10.1163/156856196X00490

14. H. Zhang, Z. Kang, J. Sang, H. Hirahara, Surf. Coat. Tech. 2018, 340, 8-16. DOI:10.1016/j.surfcoat.2018.02.005

15. N. Inagaki, S. Tasaka, T. Baba. J. Adhes. Sci. Tech. 2001, 15, 749-762. DOI:10.1163/15685610152540821

16. M. Sitting, in: Handbook of Toxic and Hazardous Chemicals and Carcinogens, Noyes Publications, William Andrew Publishing, LLC. Norwich, New York, U.S.A., 1991, p. 440-444.

17. WHO Regional Office for Europe, Air Quality Guidelines, Copenhagen, Denmark, 2000, chapter 6.4.

18. N. K. Dixit, R. Srivastava, R. Narain, Proceedings of the Institution of Mechanical Engineers, Part L: Journal of Materials: Design and Applications 2019, 233, 942-954.

DOI:10.1177/1464420717719920

19. J. Zhang, J. Feng, L. Jia, H. Zhang, G. Zhang, S. Sun, T. Zhou, ACS Applied Materials and Interfaces 2019, 11, 13714-13723. DOI:10.1021/acsami.9b01856

20. K. Ratautas, A. Jagminiene, I. Stankeviciene, E. Norkus, G. Raciukaitis, $201813^{\text {th }}$ International Congress Molded Interconnect Devices 2018, 8526970.

DOI:10.1109/ICMID.2018.8526970

21. S. Chen, Q. Zhu, Y. Zhao, J. He, G. Wang, Materials and Corrosion 2019, 70, 720-725.

DOI:10.1002/maco.201810485

22. X. Han, G. Wang, Y. He, Y. Wang, Y. Qiao, L. Zhang, Journal of Adhesion Science and Technology 2018, 32, 2481-2493.

DOI:10.1080/01694243.2018.1488460

23. X. Han, G. Wang, J. He, J. Guan, Y. He, Surface and Interface Analysis 2019, 51, 177-183. DOI:10.1002/sia.6560

24. I. Anil, S. T. Gunday, O. Alagha, A. Bozkurt, Journal of Polymers and the Environment 2019, 27, 1086-1095.

DOI:10.1007/s10924-019-01415-0

25. J. Li, S. Wang, F. Liu, X. Wang, H. Chen, T. Mao, Z. Wang, Journal of Membrane Science 2019, 581, 303-311.

DOI:10.1016/j.memsci.2019.03.025

26. K. Kang, D. Kim, Journal of Membrane Science 2019, 578, 103-110. DOI:10.1016/j.memsci.2019.02.043

27. E. A. M. Azmy, H. E. Hashem, E.A. Mohamed, N. A. Negm, Journal of Molecular Liquids 2019, 284, 748-754.

DOI:10.1016/j.molliq.2019.04.054

28. A. Blivernitz, T. Förster, S. Eibl, Polymer Testing 2019, 76, 261-272. DOI:10.1016/j.polymertesting.2019.03.009
29. X. Yu, Z. Wang, J. Liu, H. Mei, D. Yong, J. Li, Materials Today Communications 2019, 19, 124-130.

DOI:10.1016/j.mtcomm.2018.12.015

30. R. Kessentini, O. Klinkova, I. Tawfiq, M. Haddar, Polymer Testing 2019, 75, 159-166.

DOI:10.1016/j.polymertesting.2019.01.013

31. S. H. Kamarul Bahrain, J. Mahmud, Materials Letters 2019, 242, 32-34. DOI:10.1016/j.matlet.2019.01.100

32. Q. Qiang, X. Geng, Z. Wang, Journal of Adhesion Science and Technology 2019, 33, 371-381.

DOI:10.1080/01694243.2018.1507318

33. X. Sun, L. Zhang, S. Tao, Y. Yu, S. Li, H. Wang, J. Qiu, Advanced Materials Interfaces 2017, 4, 1700052.

DOI:10.1002/admi.201700052

34. H. Pang, R. Bai, Q. Shao, Y. Gao, A. Li, Z. Tang, Applied Surface Science 2015, 359, 280-287.

DOI:10.1016/j.apsusc.2015.10.100

35. S. M. Simon, A. Chandran, G. George, M. S. Sajna, P. Valparambil, E. Kumi-Barmiah, G. Jose, P. R. Biju, C. Joseph, N. V. Unnikrishnan, ACS Omega, 2018, 3, 14924-14932.

DOI:10.1021/acsomega.8b01940

36. N. Gao, X. Zhang, S. Liao, H. Jia, Y. Wang, ACS Macro Letters 2016, 5, 823-827.

DOI:10.1021/acsmacrolett.6b00338

37. E. B. Saubestre, in: F. A. Lowenheim (Ed.): Modern Electroplating, Wiley-Interscience Publication, New York, 1995, chapter 28.

38. R. K. Wahi, W. W. Yu, Y. Liu, M. L. Mejia, J. C. Falkner, W. Nolte, V. L. Colvin, J. Molecular Cataly. A: Chem. A 2005, 242, 48-56. DOI:10.1016/j.molcata.2005.07.034

39. W. Zhao, J. Ding, Z. Wang, Langmuir 2013, 29, 5968-5973. DOI:10.1021/la400321k

40. M. Piton, A. Rivaton, Polymer degradation and stability 1996, 53, 343-359. DOI:10.1016/0141-3910(96)00093-6

41. J. L. Gardette, B. Mailhot, J. Lemaire, Polymer degradation and stability 1995, 48, 457-470.

DOI:10.1016/0141-3910(95)00113-Z

42. M. Piton, A. Rivaton, Polymer degradation and stability 1997, 53, 147-157. DOI:10.1016/S0141-3910(96)00116-4

43. J. F. Rabek, Polymer photodegradation: Mechanisms and experimental methods. Chapman and Hall. London, UK, 1995, Chapter 2. 


\section{Povzetek}

Površinska modifikacija kopolimernih substratov iz akrilonitril-butadien-stirena (ABS) je pomembna za industrijo galvanizacije. Kopel mešanice žveplove kisline in kromovega(VI) oksida, ki se uporablja v postopku priprave površine ABS s selektivno oksidacijo polibutadiena ustvarja med seboj povezane mikro pore, kar omogoča odlično mehansko adhezijo med kovinsko folijo in podlago. Šestvalentni krom (Cr (VI)) je škodljiv za ljudi in okolje in je kancerogen. V prispevku raziskujemo spremembe površine $\mathrm{z}$ različnimi tipi kemijskih reagentov na površino ABS in njegovo obdelavo v kopeli mešanice žveplove kisline in kromovega(VI) oksida v koncentracijah, ki so nižje od uporabljenih v običajnih procesih. $\mathrm{Z}$ uporabo različnih preučevanih kemijskih reagentov se je površina ABS spreminjala, kar je povzročilo različne vrste reakcij na površini, ki so lahko potekale spontano ali med postopkom priprave površine.

Except when otherwise noted, articles in this journal are published under the terms and conditions of the Creative Commons Attribution 4.0 International License 